\title{
BMJ Open The feasibility and potential use of case- tracked client journeys in primary healthcare: a pilot study
}

\author{
Elsa Barton, ${ }^{1,2}$ Toby Freeman, ${ }^{2}$ Fran Baum, ${ }^{2}$ Sara Javanparast $^{2}$ Angela Lawless ${ }^{3}$
}

To cite: Barton E, Freeman T, Baum F, et al. The feasibility and potential use of casetracked client journeys in primary healthcare: a pilot study. BMJ Open 2019;9:e024419. doi:10.1136/ bmjopen-2018-024419

- Prepublication history and additional material for this paper are available online. To view these files, please visit the journal online (http://dx.doi org/10.1136/bmjopen-2018024419.

Received 25 May 2018 Revised 15 April 2019 Accepted 17 April 2019
Check for updates

(C) Author(s) (or their employer(s)) 2019. Re-use permitted under CC BY-NC. No commercial re-use. See rights and permissions. Published by BMJ.

${ }^{1}$ Flinders University Rural Health South Australia, Flinders University, Mt Gambier, South Australia, Australia

${ }^{2}$ Southgate Institute for Health, Society \& Equity, Flinders University, Adelaide, South Australia, Australia

${ }^{3}$ Speech Pathology, School of Health Sciences, Flinders University, Adelaide, South Australia, Australia

Correspondence to

Dr Elsa Barton;

elsa.barton@flinders.edu.au

\begin{abstract}
Objectives To determine the feasibility of case-tracking methods in documenting client journeys at primary healthcare (PHC) services in order to investigate the comprehensiveness of service responses and the experiences of clients.

Design Prospective pilot study. Quantitative and qualitative case management data were collected from staff via questionnaire or interview.

Setting Five Australian multidisciplinary PHC services were involved including four South Australian statemanaged and one Northern Territory Aboriginal community-controlled PHC service.
\end{abstract}

Participants Clients using services for depression (95) or diabetes (185) at the PHC services were case tracked over a 12-month period to allow construction of client journeys for these two conditions. Clients being tracked were invited to participate in two semi-structured interviews (21) and complete a health log.

Results Though a number of challenges were encountered, the case-tracking methods were useful in documenting the complex nature of client journeys for those with depression or diabetes accessing PHC services and the need to respond to the social determinants of health. A flexible research design was crucial to respond to the needs of staff and changing organisational environments.

Conclusions The client journeys provided important information about the services' responses to depression and diabetes, and about aspects unique to comprehensive PHC such as advocacy and work that takes into account the social determinants of health.

\section{INTRODUCTION}

A client journey is a map of the steps a client takes as he or she progress through different stages of a disease, often capturing diagnosis and management and interactions with health professionals. ${ }^{1}$ The idea of a client journey has become widespread as the prevalence of chronic illnesses has increased in frequency. ${ }^{2}$ The result has been a change in the way people interact with health services, from relatively 'short and sharp encounters' to more people commencing journeys that may take years or decades of care. ${ }^{2}$ There is increasing recognition that the healthcare

\section{Strengths and limitations of this study}

This pilot study trialled multi-method case tracking that potentially provides a more thorough picture of the client journey that includes service data, client perspectives and health logs.

- A strength of the case tracking was its ability to be applied to the varied size of the organisations studied.

- The study was limited to tracking clients within one primary healthcare service rather than across multiple organisations due to the complex service delivery structures that make up the Australian health system.

- The case tracking was not able to include health outcome measures but does have the potential to provide a strong contribution to evaluations of service models.

journey itself, not only at the beginning (first symptoms, seeking help, getting a diagnosis) but also the process and experiences along the way, is important for healthcare outcomes. ${ }^{34}$

Despite the increased attention to mapping client journeys, the concept varies and different terms tend to be used interchangeably. ${ }^{5}$ Common terms used are "patient journey', 'patient pathway', 'referral pathway' and 'patient care pathway'. These terms differ from 'integrated care pathways' and 'care pathways', which outline an agreed plan developed by a multidisciplinary team and may include client or carer involvement of anticipated care or client satisfaction feedback. ${ }^{5-7}$ In this paper, we use the term client as this research took place in services based in the community where the term client journey is used. ${ }^{8}$

Case-tracking methods allow the construction of client journeys by tracking individuals for a period of time from commencement at a service to when they finish or for a determined period of time. It involves the use of multiple methods, using quantitative and qualitative data from a number of sources. ${ }^{9}$ Case-tracking 
methods have been used to understand case management of child protection, ${ }^{9-13}$ and in health settings, including in hospitals,${ }^{14}$ following hospital discharge ${ }^{15}$ and outpatient clinics. ${ }^{16}$ Common methods include the use of one or more of the following sources: auditing electronic records; interviews with clients, carers and health professionals; direct observation and health logs. Using a combination of these methods has been termed 'walking the patient journey' ${ }^{14}$ and presents a comprehensive picture of what is happening for clients as well as practitioner perspectives. However, studies most often rely on single sources of information; for example, Oliver et $a l^{17}$ used client recall through telephone interviews to map the journeys of clients with rheumatoid arthritis and Richards et $a l^{18}$ extracted data from local National Health Service sites to describe pathways through stepped care services for clients with depression and anxiety.

We sought to examine the applicability of multi-method case tracking to understand client journeys in primary healthcare (PHC). Use of multiple methods achieves a more thorough picture of the client journey that includes service data, client perspectives and health logs. The results are potentially very valuable, as there is generally a lack of evidence about the experiences of people receiving multidisciplinary PHC services over time. Mapping the client journey through multi-method case tracking that includes gathering client perspectives through qualitative interviews may be a useful way to understand client experiences in $\mathrm{PHC}$ and has the potential to improve health services.

We trialled the case-tracking method to generate client journeys within multidisciplinary PHC services as part of a larger project examining ways to evaluate the effectiveness of comprehensive PHC services. Comprehensive PHC is an approach to service delivery and health promotion underpinned by a social view of health, community participation, empowerment, social justice, equity and action on social determinants of health. ${ }^{19} 20$ Hence, comprehensive PHC services would be expected to engage in a wider set of activities with clients that not only includes clinical care, but also incorporates health promotion groups, advocacy and community development. We were interested in how comprehensive our case study PHC services were in practice, and sought to expand existing case-tracking methods to include examination of this range of comprehensive PHC strategies. Two key chronic conditions were selected as example health issues: diabetes and depression.

Chronic diseases such as diabetes and depression pose significant health problems, and both require ongoing care and management. Comprehensive PHC offers a valuable approach to addressing diabetes and depression given its holistic, whole of sector approach emphasising principles of promotion, prevention and early intervention, multidisciplinary team work and community participation.

Health services have a central role in developing and supporting self-management skills of individuals with these conditions to enhance health and well-being outcomes. The ability to self-manage is heavily dependent on the broader social and economic context of peoples' living circumstances. ${ }^{21}$ Health services have been urged to take social determinants of health into consideration including social support, financial resources and housing that all influence self-management, ${ }^{21}$ and comprehensive PHC holds promise as a model for achieving this. Analysis of client journeys provided a means of examining how this philosophy of care and health promotion played out in practice for users of comprehensive PHC services. This paper focuses on the feasibility of using multi-method case tracking and discusses key learnings from its application. These key lessons on how to research client journeys can be used to examine different service models. They also potentially lead to a better understanding of the gaps in quality of care and may inform efforts to improve service delivery. This pilot sought to answer the following research questions:

1. How can case-tracking data be feasibly collected from PHC services, including client perspectives, and used to construct client journeys for people with depression and diabetes, in order to capture the range of work comprehensive PHC may engage in with clients?

2. What can be learnt from client journeys for depression and diabetes about the care received and experiences of clients, and how can this inform the evaluation of $\mathrm{PHC}$ service delivery for these two health issues?

\section{METHODS}

\section{Case study services}

Case-tracking methods were piloted to track the journey of clients that accessed care for depression and diabetes at five case study Australian PHC services. These sites were an Aboriginal community-controlled health organisation, Central Australian Aboriginal Congress Aboriginal Corporation, Northern Territory ('Congress'), which requested to be named in publications; and four PHC services funded by the South Australian government (A, C, D-an Aboriginal health team-and E), which requested service anonymity. Service B (also a South Australian government funded PHC service) withdrew from the study due to significant organisational change when the case-tracking methods were being negotiated. These case study sites were chosen as they represent both long-standing and emerging models of PHC delivery in Australia, and are described in more detail elsewhere. ${ }^{22} 23$ In brief, the services were multidisciplinary teams ranging from 10 (service A) to 320 staff (Congress). The variation in size of the sites was indicative of the nature of PHC services in Australia with there being no standard publically run services.

This research took place while there was considerable change in the Australian healthcare system. During the period of research, there was a restructure and rapid reorientation of PHC services from a broad approach to a narrow interpretation of PHC with a focus on physical 
chronic conditions. These changes are documented elsewhere ${ }^{24}$ and made the research context particularly challenging.

\section{Overview of case-tracking and client interview methods}

We adapted Tomison and Goddard's ${ }^{9}$ case-tracking methods to track the journeys of clients that accessed care for depression or diabetes at each of the services over a 12-month period. Tomison and Goddard ${ }^{9}$ developed this case-tracking method in their study of the Victorian child protection system where child protection case management and decision-making models were developed. One key difference was that Tomison and Goddard tracked cases across multiple organisations, whereas we could track only clients seeing multiple professionals at one service. We looked at what referrals were made to other services but we were unable to track clients at these services. This was largely due to the complex service delivery structures that form the Australian health system with a mix of public and private funds shared between the states, federal and local governments that made tracking across multiple organisations not possible and beyond the scope of this study. While the general principle of Tomison and Goddard's case-tracking method was followed, we developed our own questionnaires with open-ended and close-ended questions to answer our research questions on comprehensiveness of care, and provided a range of flexible options to collect these data from staff. As client perspectives were central to our research questions, client interviews and client healthcare logs were added to complement the case tracking (stage 2). This log was adapted from health diaries used by Veale ${ }^{25}$ in her research investigating general practice utilisation in Australia. Health logs were a useful way of supplementing data captured during client interviews and have been used in other studies documenting client journeys. ${ }^{15}$ This multi-method design was used to provide the multiple perspectives necessary to "walk the client journey. ${ }^{14}$ Table 1 lists the stages of data collection and the case-tracking tools used at each service.
Prior to the case-tracking commencing, there were multiple meetings at each service to negotiate and gain feedback on the feasibility of the methods, health professional workloads and approval from managers for staff to be involved. A 'champion'-a key contact person-was identified at each PHC service to liaise with researchers and help organise the research at their site. Once data collection had been established at each site, regular phone calls and meetings were held to discuss progress, monitor and negotiate workload issues and to keep staff informed about the research. The research team consisted of university researchers with considerable experience working in health service evaluation and with qualitative interview methods.

\section{Patient and public involvement}

The research was developed in partnership with some of the services (Congress, services $\mathrm{B}$ and $\mathrm{C}$ ). While health professionals did not participate in the analysis or as authors, the case-tracking methods undertaken by researchers was co-designed with service managers, and health professionals provided data. Clients were not involved in the design of this project. The wider project engaged with the services through twice-yearly critical reference group meetings that included managers of the services and through regular site visits by the project manager to attend health professional meetings. Casetracking data were fed back to the services (managers and health professionals) through interim and final reports. Interview guides and health logs were piloted with a group of clients with depression and diabetes from another PHC service not involved in this project to gain feedback on these methods prior to their use. Diabetes and depression client journeys were not fed back to clients.

\section{Stage 1: case-tracking methods}

Health professionals seeing clients for depression or diabetes (one-to-one self-management support, counselling and/or group work such as diabetes education groups) at the five sites were invited to participate in the

Table 1 Overview of case-tracking tools at each service

\section{Stage 1}

\section{Services A, B, C, D C Case-tracking questionnaire (see online supplementary A)}

Health professionals to complete a questionnaire for each client they see with depression or diabetes

\section{Stage 2}

Client interviews and health log

Clients being case tracked are invited to participate in a semi-structured interview (online supplementary $B)$ early on in their journey and maintain a health log (online supplementary $\mathrm{C}$ ) for 6 months or until they stop coming to the service. A second interview (online supplementary D) is scheduled to discuss their experiences of the service and their health log

Congress
Research assistant accesses deidentified data
for clients with depression or diabetes from
Communicare (client database)
Health professionals complete a short reflective
questionnaire (online supplementary E)


study. Health professionals recorded the number of times per month they saw clients with depression or diabetes. Clients were tracked for a period of 12 months or until they stopped using the health service.

Health professionals agreeing to participate chose electronic questionnaires, mailed paper questionnaires or monthly interview where questionnaires were completed for all the clients seen for depression or diabetes in the last month. The questionnaires collected information on elements of comprehensiveness and drew on comprehensive PHC literature, and a programme logic model which was developed to evaluate the PHC services against. ${ }^{26}$ Both close-ended questions and open-ended questions were used to allow greater flexibility. The questions covered how the client came to use the service, relevant social determinants of health (eg, housing and employment), internal or external services health professionals were aware clients had accessed, referrals made (health or social determinants of health related) and any contact with internal or external professionals. A reflective section also captured how sessions went, what went well, what could have been done differently and any issues staff felt powerless to influence.

Health professionals and clients were deidentified by a code that was attached to questionnaires. When a referral was made within the service, the newly involved health professional also completed the questionnaire/interview each time they saw the client. This method captured when more than one worker was involved (either simultaneously or consecutively) and monitored the clients' pathway through the service.

Each client's journey was treated separately so individual client pathways through the service could be examined. At the non-Aboriginal-specific services ( $\mathrm{C}, \mathrm{A}$ and $\mathrm{E})$, who tended to see clients for a discrete period of time, the start of a clients' journey was the date they started seeing a health professional for depression or diabetes. This was not necessarily the initial onset of their depression or diabetes. At the Aboriginal PHC services (service $\mathrm{D}$ and Congress) where there were GPs on site, clients were long-term users of the services and therefore those tracked were generally not new to the service.

For the depression case tracking, 13 of the 17 staff across all South Australian services agreed to participate. It was estimated that services $\mathrm{A}, \mathrm{C}$ and $\mathrm{E}$ saw approximately 10 new clients with depression per month. Eleven health professionals seeing clients with depression agreed to meet with the researcher monthly to administer casetracking questionnaires. The remaining two health professionals completed paper questionnaires.

The diabetes case-tracking methods varied as the number of new clients seen per month with diabetes was much larger compared with the depression numbers. At the non-Aboriginal services (C, A and E), all 29 health professionals invited agreed to participate. Similarly, at service $\mathrm{D}$, all four health professionals who were involved in diabetes management were invited and they agreed to participate. The number of new referrals for diabetes
Table 2 Health professionals employed at each primary healthcare service in 2013

\begin{tabular}{ll}
\hline $\begin{array}{l}\text { Health } \\
\text { service }\end{array}$ & Practitioners employed \\
\hline Service A & $\begin{array}{l}\text { Diabetes nurse educator, primary healthcare } \\
\text { nurse, dietician, exercise physiologist, } \\
\text { podiatrist, social worker, psychologist, speech } \\
\text { pathologist, physiotherapist }\end{array}$ \\
Service C & $\begin{array}{l}\text { Primary healthcare nurse, dietician, exercise } \\
\text { physiologist, psychologist, social worker, } \\
\text { podiatrist }\end{array}$ \\
Service D & $\begin{array}{l}\text { General practitioner, nurse, Aboriginal health } \\
\text { worker, Aboriginal primary mental health } \\
\text { support worker }\end{array}$ \\
Service E & $\begin{array}{l}\text { Social worker, dietician, primary healthcare } \\
\text { nurse, exercise physiologist }\end{array}$ \\
Congress & $\begin{array}{l}\text { Medical officer, Aboriginal health worker, } \\
\text { dietician, podiatrist, psychologist, diabetes } \\
\text { nurse/nurse educator, renal primary healthcare } \\
\text { nurse, other nurses, pharmacist, dentist, } \\
\text { optometrist, specialist physician }\end{array}$ \\
\hline
\end{tabular}

was estimated between 25 and 100 per month. It was not feasible to track all these clients, therefore the first 10 new clients per month were selected by administrative staff to track for a 12-month period. The administrative staff notified health professionals of case-tracked clients and conducted audits to monitor completeness in terms of matching client appointments to a record of questionnaires completed and followed up any staff who had questionnaires outstanding.

At Congress, the approach to case tracking differed as health professionals reported considerable existing research data collection burdens. Health professionals were not invited to participate; instead, deidentified data for diabetes and depression clients were obtained from Communicare, an electronic client record system used at this health service. To complement the routine data collected, health professionals were asked to complete a short qualitative questionnaire, reflecting on their practice. The range of health professionals employed at the five sites is shown in table 2).

\section{Analysis of client journeys}

Case-tracking questionnaires were imported into Excel and grouped by deidentified client codes. Flowcharts in Microsoft Word were constructed, and qualitative reflections and comments from health professionals were added as annotations on the client journey diagrams. Client journeys were analysed against an evaluation framework of questions developed to examine evidence for the different comprehensive PHC attributes such as accessible, mix of treatment, prevention and promotion, multidisciplinary care, intersectoral collaboration, advocacy and cultural respect and action on social determinants of health. Analysis of client journeys was guided by Miles, Huberman and Saldana ${ }^{27}$ approach to developing 
matrices with defined rows and columns which were used to compare service responses to depression and diabetes and alignment with the evaluation framework. The use of matrices enabled us to condense data into a few pages that could be easily viewed and enabled detailed analysis of response patterns that were examined within and between the services. Within-case and cross-case analyses were applied where the range of responses provided by the services to participants were documented using comprehensive PHC attributes of the evaluation framework. Cross-case analysis then followed with thematic analysis applied across cases. Matrices were used to compare and contrast themes and interpret short-term and long-term consequences as well as the extent of comprehensive PHC implementation among these PHC services.

\section{Stage 2: client interviews and healthcare log}

Health professionals invited a selection of clients being tracked to participate in (1) a semi-structured interview early on in their journey, (2) to maintain a $\log$ of healthcare received for 6 months-from the PHC service or other services, (3) a second interview covering their experience of receiving healthcare in the intervening 6 months. Six months was chosen to allow a significant period of time to study clients' experiences, while not wanting to reduce data completeness, or participant engagement and retention that a longer time frame may have risked. Health professionals purposefully sampled to maximise diversity to aim for a range of age, gender and living circumstances when inviting clients with diabetes to the interview component of the research. Due to the lower than anticipated number of clients with depression accessing the services, health professionals were asked to invite all clients with depression who were being tracked to participate in the interviews. At the first interview, clients were provided with a healthcare log to complete each time they saw a health professional. Different options such as an electronic log, pen and paper and a pictorial log were given to allow for low English literacy. Clients were contacted monthly by researchers as a reminder to complete the $\log$ which was then discussed at the second interview.

\section{Analysis of interviews}

Client interview data were analysed by researchers in QSR Nvivo using thematic analysis guided by a number of key service qualities and mechanisms that underpin a comprehensive PHC approach. Analysis of client interview data was guided by the 'Framework' method. ${ }^{28}$ Analysis started with familiarisation and identifying a thematic framework. During this stage, meetings were held with the research team to reach an agreement on emergent themes. 'Indexing' or coding of the whole dataset then took place according to the thematic framework. Charts were developed where data were 'lifted' from the transcripts to a table in Microsoft Word with headings according to core themes and based on the research questions. Interpretation and mapping then took place where client perceptions and experiences at the PHC services were compared and contrasted. Charts where interpreted alongside the client journeys to seek explanations and interpret the dataset as a whole. Clients were given pseudonyms to assure anonymity.

\section{RESULTS}

A total of 95 depression client journeys in the five PHC services were documented and 28 participants were interviewed (see table 3 ). The majority were female $(76 \%)$ and the average age was 45 years (range 23-67 years). For the non-Aboriginal-specific services, the majority of clients were new to the health services and had recently

Table 3 Number of depression clients case tracked and interviewed at each primary healthcare service

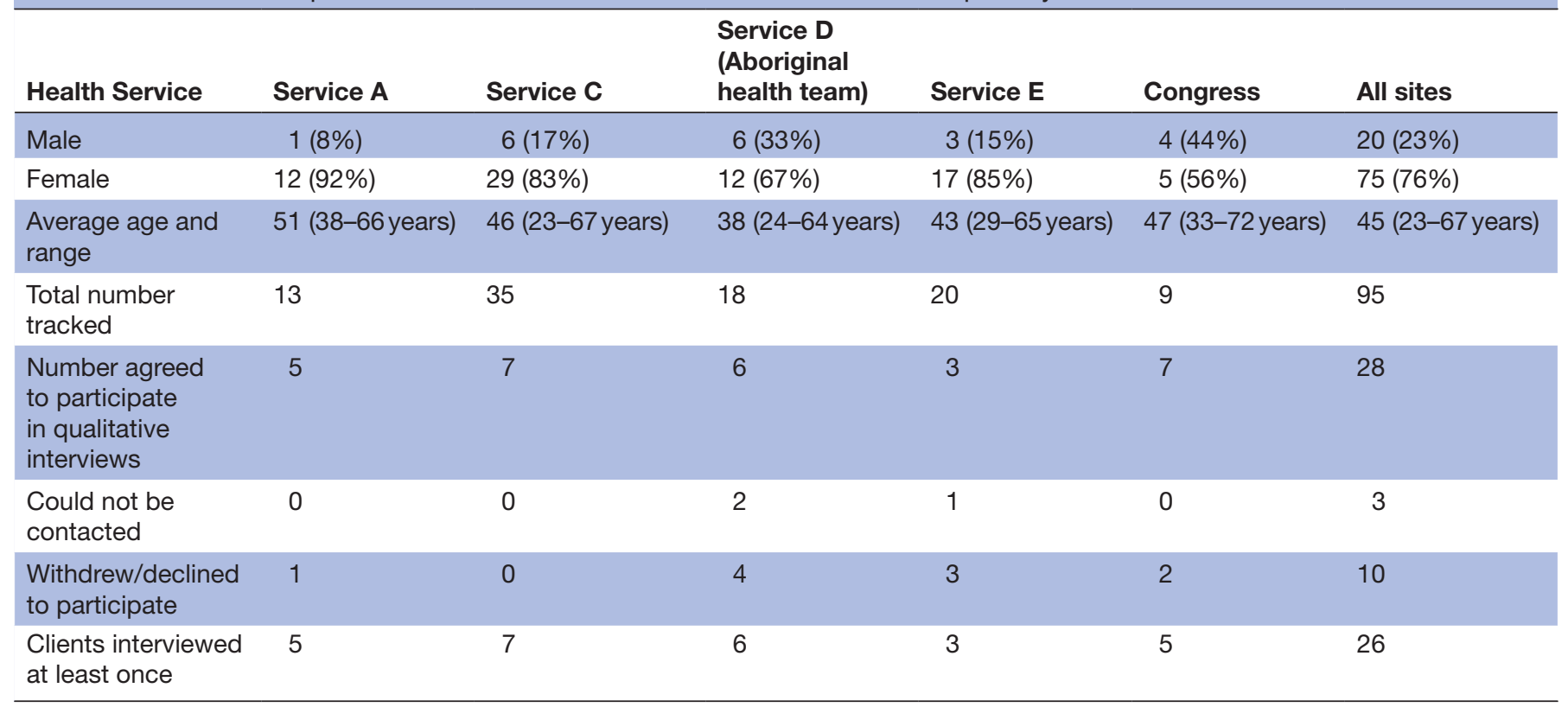


Table 4 Number of diabetes clients case tracked and interviewed at each primary healthcare service

\begin{tabular}{lllllll}
\hline Health service & Service A & Service C & $\begin{array}{l}\text { Service D } \\
\text { (Aboriginal } \\
\text { health team) }\end{array}$ & Service E & Congress & All sites \\
\hline Male & $26(38 \%)$ & $37(60 \%)$ & $6(30 \%)$ & - & $15(50 \%)$ & $84(45 \%)$ \\
\hline Female & $42(62 \%)$ & $25(40 \%)$ & $14(70 \%)$ & - & $15(50 \%)$ & $96(56 \%)$ \\
\hline Average age and range & $57(19-85)$ & $58(25-87)$ & $53(27-81)$ & - & $55(21-81)$ & $55.75(27-81)$ \\
\hline $\begin{array}{l}\text { Total number tracked* } \\
\text { Number of qualitative }\end{array}$ & 71 & 63 & 21 & - & 30 & 185 \\
interviews & 13 & 9 & 5 & 3 & 16 & 46 \\
$\begin{array}{l}\text { Could not be contacted } \\
\text { Withdrew/declined to }\end{array}$ & 4 & 1 & 1 & 0 & 0 & 6 \\
participate & 0 & 1 & 0 & 0 & 4 & 5 \\
Clients interviewed & 9 & 7 & 4 & 3 & 12 & 35 \\
\hline
\end{tabular}

*Service A: three clients' gender not recorded; Services C, D: one client gender not recorded.

started using services for depression. This included receiving one-to-one services for depression and for some, accessing promotion and prevention services to assist them to prevent their depression reoccurring. Promotion and prevention services were offered in small groups on a range of topics such as healthy eating, exercise, mindfulness, meditation, domestic violence, smoking cessation and parenting before funding cuts to these services occurred halfway through data collection. Interviews with clients across the sample strongly emphasised benefits such as the skills they gained and improved social connection from attending these groups.

There were 185 diabetes client journeys across five PHC services (table 4), and 46 clients were interviewed. Due to the lack of monitoring of clients by the PHC services, we were unable to examine whether clients dropped out of the case tracking. It was unknown why clients stopped coming, whether they had dropped out or had received the services they needed and did not require further appointments. There were some clients who participated in an initial interview and started completing health logs and then did not continue. For both the depression and diabetes case tracking in South Australia, there was a 95\% completion rate with one client with diabetes and one client with depression unable to be contacted for the second interview. At Congress, there was a $50 \%$ completion rate for the depression case tracking where three clients disengaged from the service and were unable to be contacted, and a $58 \%$ completion rate for the diabetes case tracking where five clients either moved away or ill health prevented them attending the second interview.

\section{Overview of depression and diabetes client journeys}

Overall, the client journeys highlighted a range of different pathways for clients accessing services for depression at the PHC services. Clients had different levels of need that was reflected in the client journeys. There were greater referrals and communication to external services at service D and Congress, which may reflect greater level of need and/or a more comprehensive, integrated approach to service delivery. The client journeys from service $\mathrm{D}$ and some from service A showed some comprehensive aspects prior to health system reforms that occurred halfway through the study.

The diabetes client journeys indicated a range of intensity of healthcare provision and social supports that were provided, from a single support session with a diabetes nurse educator and dietician (figure 1) through to clients who saw different health professionals, for example, 'Callista' (figure 2; whose client journey was similar to the diabetes client journeys found at the other PHC services) where there were referrals, treatment and communication between practitioners within and outside the service. At Congress, clients sometimes accessed over 10 different professionals. Both the diabetes and depression journeys indicated that many clients experienced complex living circumstances, including housing issues, mental health issues and family and carer responsibilities. Figure 2 captures how the workers tried to take into account the clients' social determinants of health in their clinical care, the referrals and advice they made around these issues and their concern about their capacity to address them fully.

Cross-case analysis of case-tracking data uncovered different models of service delivery among the PHC services. There were different approaches to multidisciplinary teamwork and co-location of services seemed to support multidisciplinary care. At service D and Congress, having a GP within the health service meant clients' physical and mental health needs were considered as evidenced by the high number of referrals made within these services. In comparison, health professionals at the non-Aboriginal PHC services rarely collaborated with GPs even though there was a GP clinic co-located or adjacent to these PHC services. Internal collaboration and communication was a strength of service $\mathrm{D}$ and Congress with client journeys showing the way GPs worked with allied health 


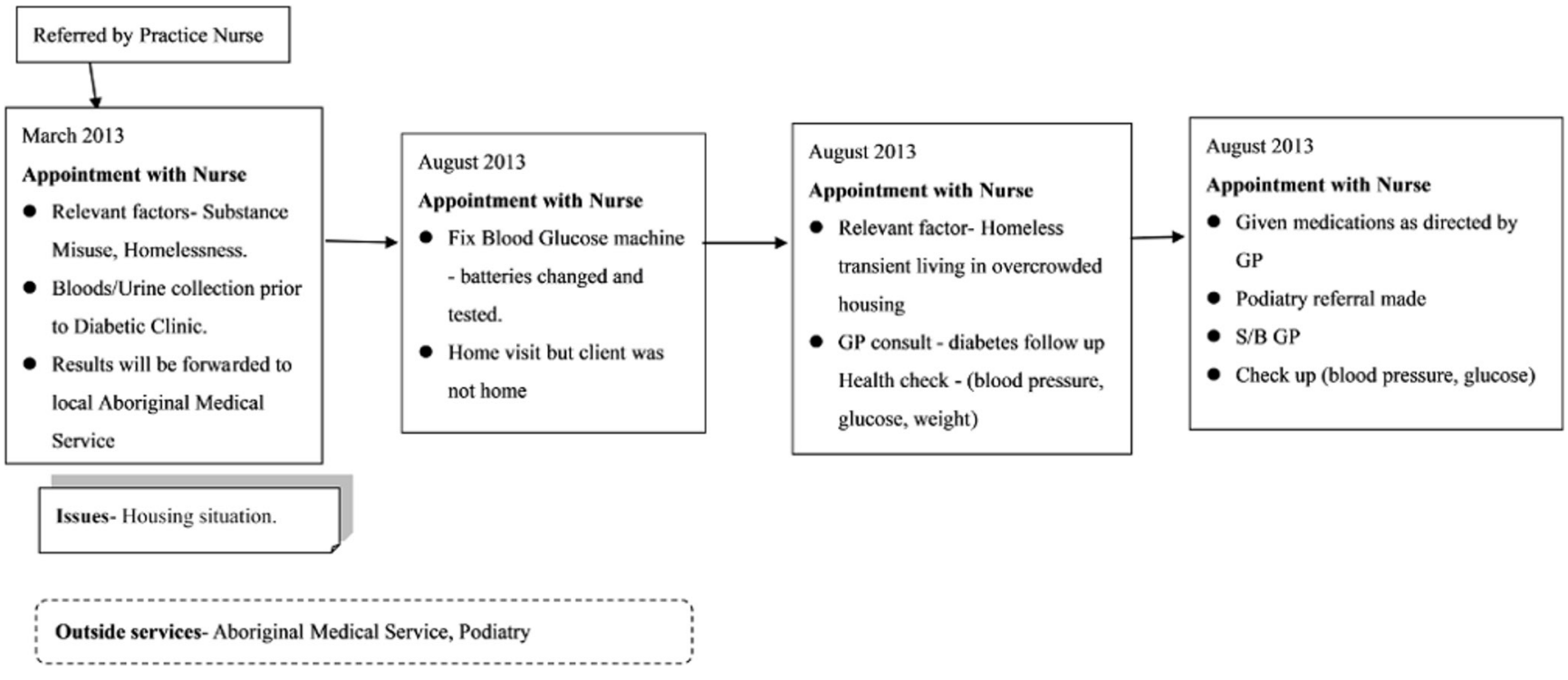

Figure 1 Example of diabetes client journey - service D: 'Desiree'. GP, general practitioner.

staff, including mental health staff, the integral role of diabetes nurse educators, PHC nurses and a number of staff collaborations internally and externally to the health services. For example, there were regular meetings and case conferences with other support services working with clients to coordinate service delivery. Groups were also a feature for some client journeys, including diabetes information groups, supermarket tours, nutrition and cooking skills, exercise groups and mindfulness and meditation.

Figures 3 and 4 show example depression client journeys of how these two health services worked with clients providing insights into their responsiveness to clients,

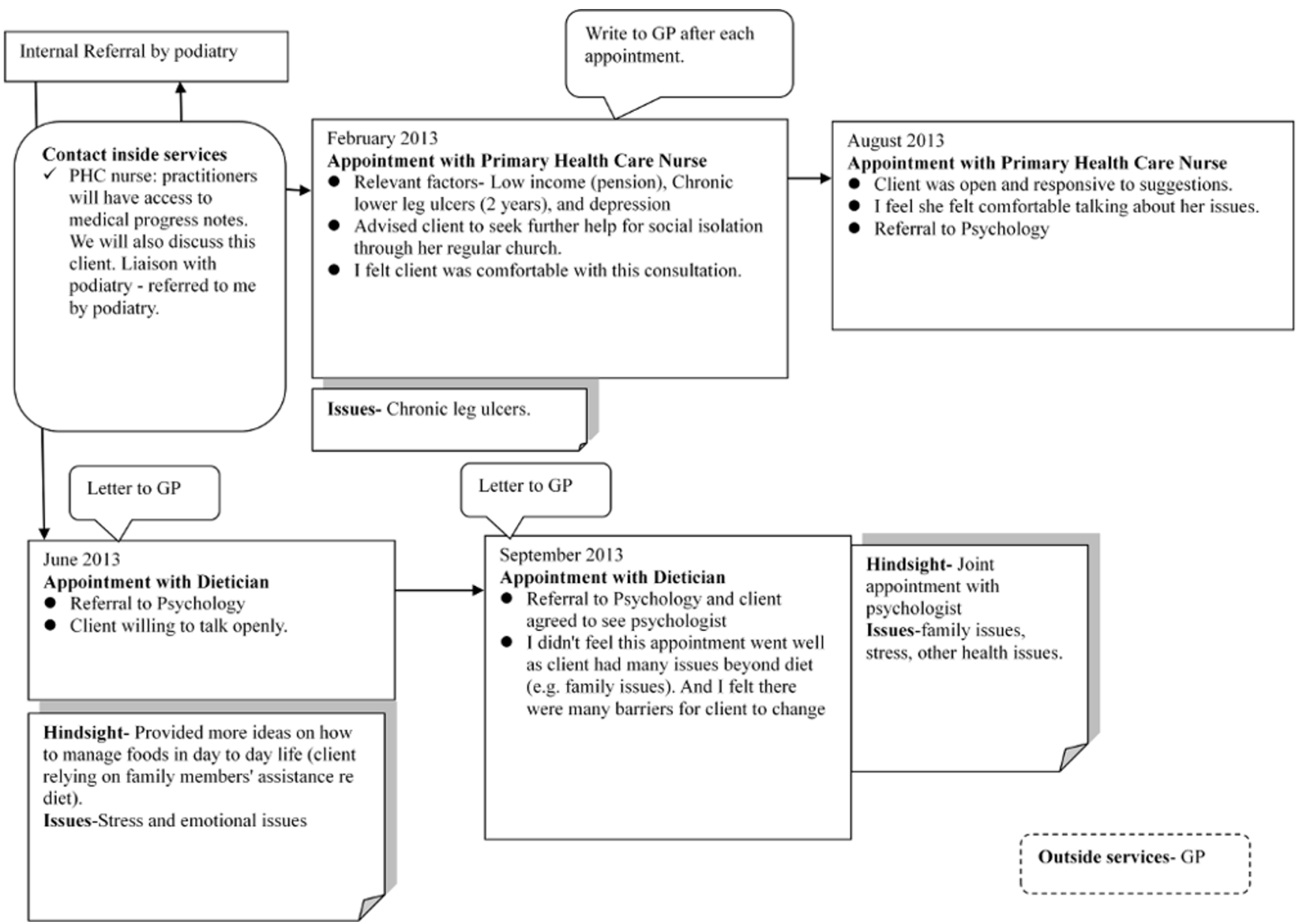

Figure 2 Example of diabetes client journey-service C: 'Callista'. GP, general practitioner; PHC, primary healthcare. 
May 2013 regular counsellor- Case discussion with

Community Well Being Team. Called client to discuss follow up

arrangements, brief counselling intervention

June 2013 GP at Women's Health branch x2

1. part adult health check, discussed depression. Review medications

2. discussed other medical condition (health promotion) assessed mood and reviewed medications

June 2013 regular counsellor $\mathbf{x} 2$

1. Counsellor hand over case management to other counsellor

2. Administration, case discussion to arrange coverage of client by Mental Health worker, while psychologist on leave

July 2013 Aboriginal Mental Health worker- received call from client requesting assistance to attend local hospital. Transport provided.

July 2013 regular counsellor/ psychologist $\mathbf{x} 3$

1. Administration, client contacted to arrange follow up appointment. Brief counselling provided.

2. Telephoned client to discuss follow up arrangements and change of case management

3. Telephoned client to discuss treatment and follow up plans and to assess general mood state. Provided brief intervention.

\section{Internal} referral

1.

September 2013 regular counsellor/ psychologist $\mathbf{x} 7$

. Outreach visit for follow up appointment. Counselling and Cognitive Behavioural Therapy provided $\mathrm{x} 2$.

2. Outreach visit for follow up appointment. Brief counselling provided - client was on way out $\mathrm{X} 1$

3. Case discussion and referral to CAMHS for review by Psychiatrist

4. Telephoned client about CAMHS appointment

5. Telephoned client to assess mood. Brief counselling

6. Telephoned client to arrange follow up appointments, no answer

Figure 3 Example of depression client journey-Congress: 'Cassie'. GP, general practitioner.

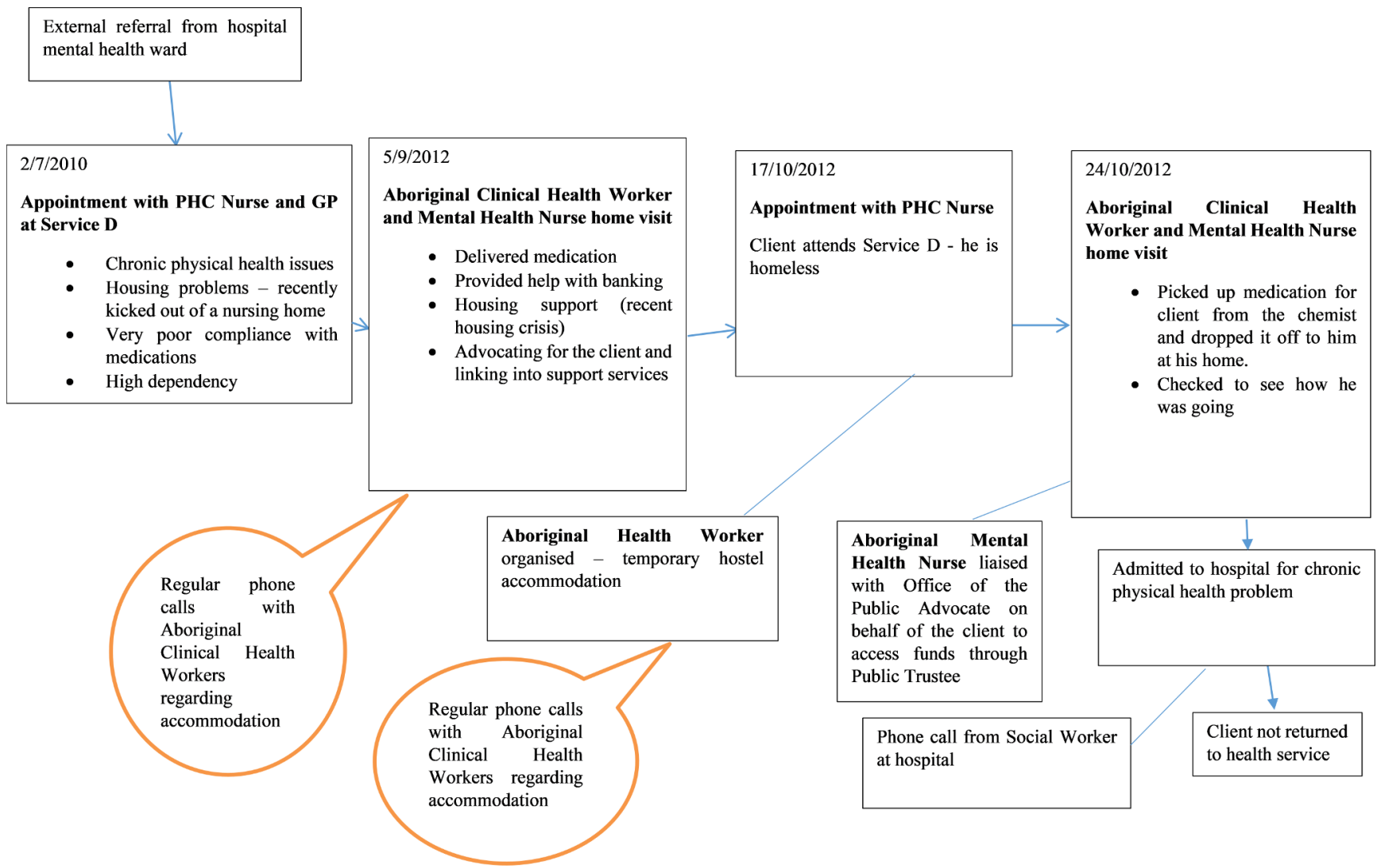

Figure 4 Example of depression client journey-service D: 'Robert'. GP, general practitioner; PHC, primary healthcare. 


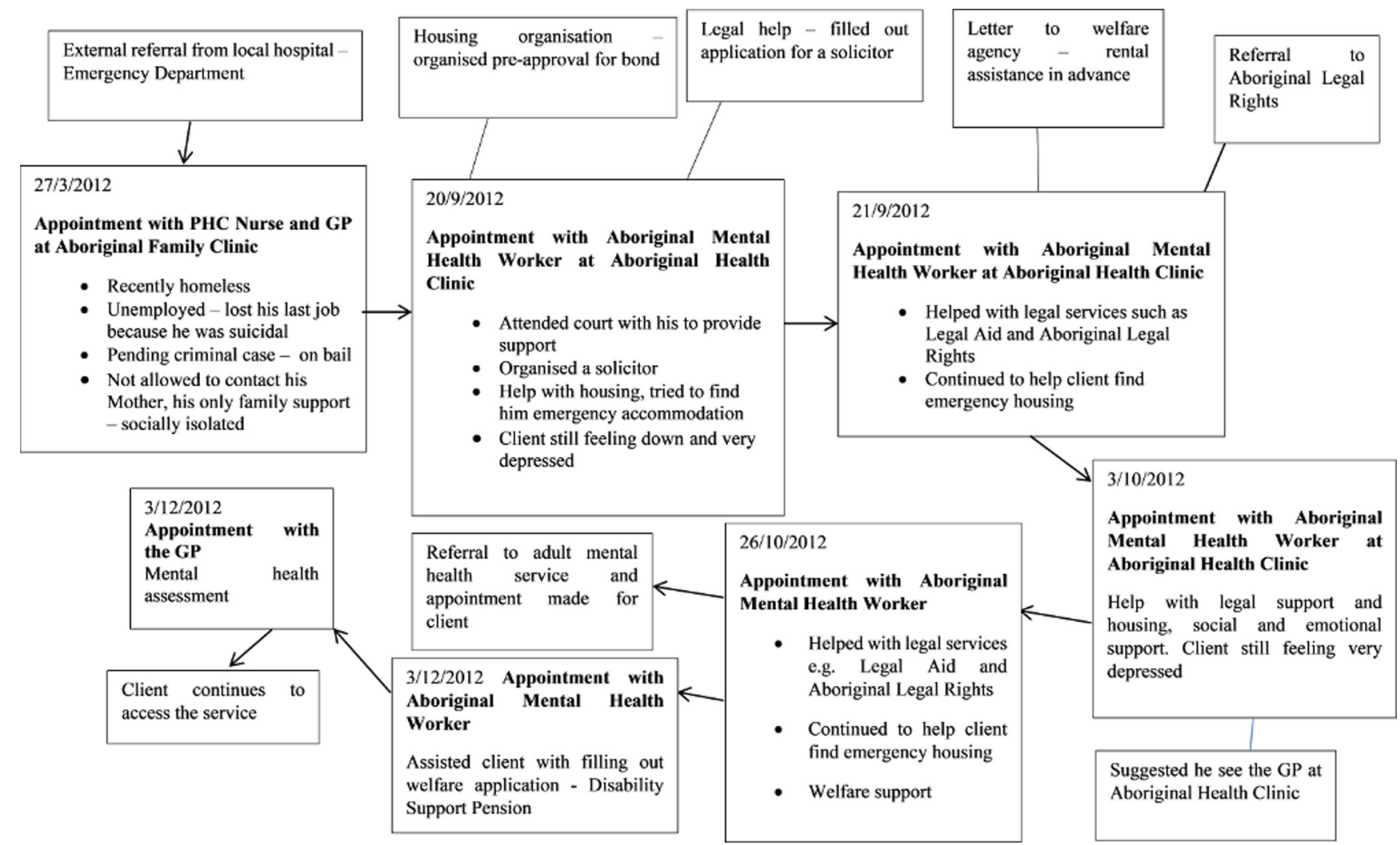

Figure 5 Example of depression client journey - service D: 'Allan'. GP, general practitioner; PHC, primary healthcare .

which was a strength at these services. Figures 3 and 4 are snapshots of these journeys and show how 'Cassie' received counselling, regular review of medications, transport to attend a local hospital and a referral to see a psychiatrist for a review of her depression. 'Robert' was provided assistance with accommodation and home visits by the Aboriginal Health Worker and Mental Health Nurse. Within-case analysis of client journeys at service D and Congress revealed many examples of ways in which these services tailored service delivery so that it was based on clients' individual needs and considered their social and economic circumstances. This included transportation to financial counselling, home visits, housing support such as linking clients to support services, advocacy on behalf of clients, for example, to the police and welfare, and encouraging attendance at health promotion/support groups to promote community connection. 'Allan' (figure 5) attended appointments with the GP and Aboriginal Mental Health Workers. Referrals were made to a mental health clinic and Aboriginal Legal Rights. The services tried to tackle social determinants by advocating on his behalf with regard to social issues such as housing, welfare and support. Advocacy and help with social issues among the PHC services was particularly an emphasis at service $\mathrm{D}$ and Congress showing this is an important aspect of their work (figures 3, 4 and 5).

At services $\mathrm{A}, \mathrm{C}$ and $\mathrm{E}$, the client journeys showed a partially implemented PHC approach that did not match comprehensive PHC ideals of holistic care and intersectoral collaboration (see figure 6 'Aden'). Service E was the only service to refer clients to health promotion and support groups in the community. Overall, PHC workers (commonly social workers or psychologists) at services A, $\mathrm{C}$ and $\mathrm{E}$ mostly worked one-to-one with clients in isolation from other professionals at the service with only a few examples of internal referrals and communication within these health services and external health referrals and communication with other agencies.

\section{DISCUSSION}

This study sought to answer how feasible it is to collect case-tracking data from PHC services that include staff and client perspectives to construct client journeys for people with depression and diabetes. The pilot casetracking methods were judged to be effective in construction of client journeys for clients accessing PHC services as multiple data sources were able to be condensed into one visual map which provided valuable information about how services responded to clients with depression and diabetes and highlighted important elements such as referral pathways, collaboration with workers within and outside the service, advocacy and how the service staff took into account the social determinants influencing clients' health. Additionally, the journeys showed the complexity of the lives of some participants, the factors that contributed to their ability to manage their depression or diabetes, such as housing issues, discrimination and racism, low income, extent of family support and social connectedness. 


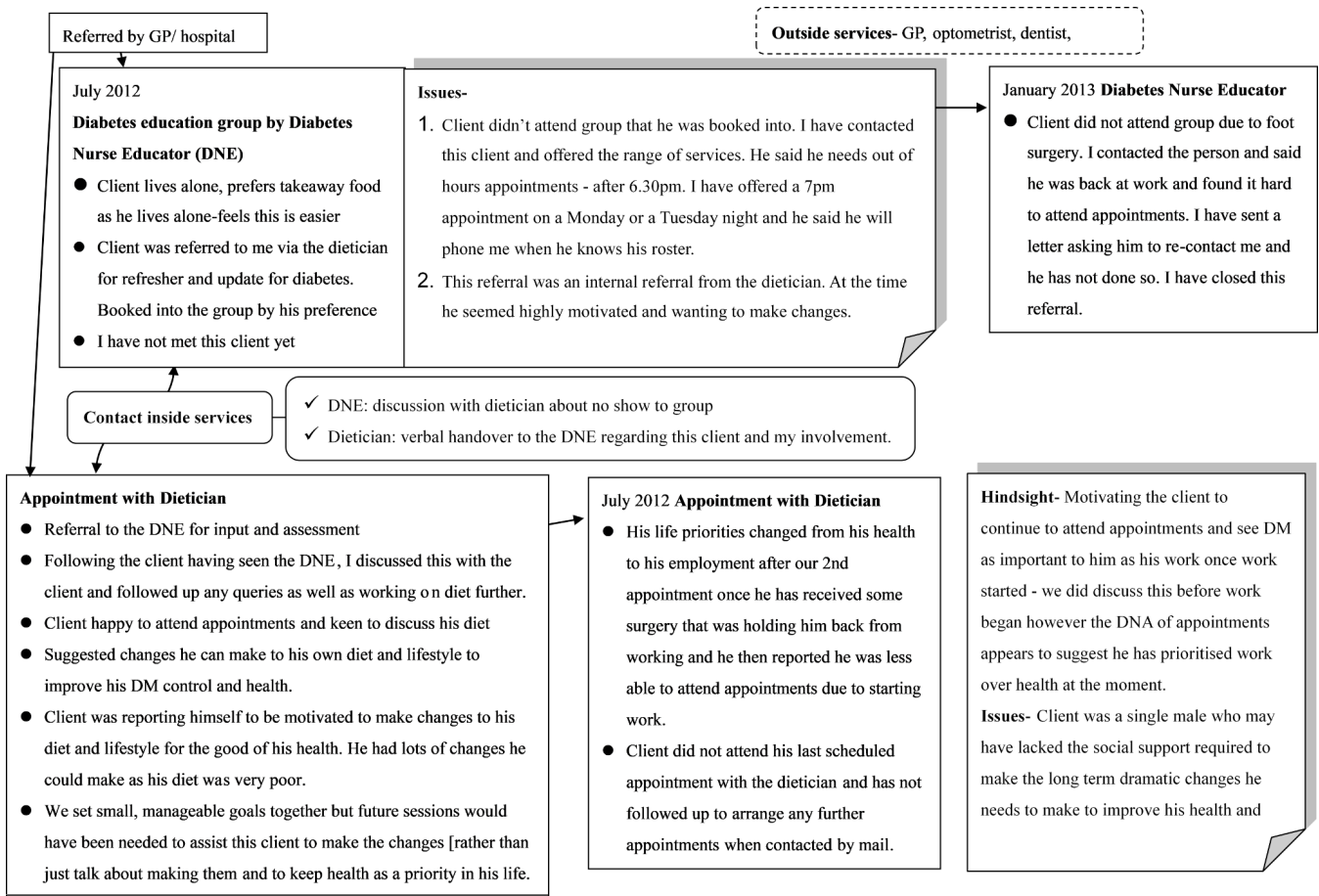

Figure 6 Example of diabetes client journey-service A: 'Aden'. DNE, diabetes nurse educator; GP, general practitioner.

This focus on the social determinants of health reflects a key principle of comprehensive PHC with the aim of reducing health inequities. The client journeys generated highlighted the broader work the services carried out to support clients such as client advocacy. This included representing the interests of clients such as help to access food and financial assistance, support letters and assistance finding housing, support and promoting client's rights during joint meetings with other services that were also working with clients, and assisting clients to access legal services and attending court hearings together with clients. Gaps were also highlighted such as a lack of referrals to other services in the community. These data were helpful as there is a lack of evidence about experiences of people receiving care at PHC services over time, and health service research focusing on clinical aspects and outcomes of care may overlook the role played by clients' social determinants of health. For example, there was no mention of the social determinants of health in patient pathways generated by Trebble $e t a l^{14}$ and Richards $e t a l^{18}$ which both had a clinical focus and emphasised efficiency and effectiveness of health services. Having an understanding of client experiences is important in enhancing the quality of care and to inform service planning and practice.

\section{What worked well with the case-tracking method}

There were a number of important aspects of the application of the case-tracking method that increased its successful application (see box 1 for a list of lessons for the application of this method in other settings). The wider project in which this research sat was developed in partnership with some of the services (Congress, services $\mathrm{B}$ and $\mathrm{C}$ ). This engagement supported the relationships needed with health professionals to collect data and invite clients for interviews, and assisted the validity, credibility and relevance of the findings. As per Guba and Lincoln's ${ }^{29}$ criteria, credibility, transferability, dependability and confirmability were used to assess the trustworthiness of the case-tracking methods. In particular, collecting data through different methods according to context and participant preference enhanced the confirmability of the data. For example, client journeys were confirmed by clients during interviews, data were gathered via casetracking questionnaires with health professionals as well as yearly audits conducted at each site that collected service data on workforce, resources, changes in funding, activities and services provided, client numbers and the partnerships and collaborations with other agencies. As a result, the triangulation of these data enabled an examination of the service responses to depression and diabetes over the care trajectory.

\section{Box 1 Key lessons for the application of case-tracking} methods in other settings

- Case-tracking methods co-designed and developed in partnership with health services.

- Being flexible in how data are collected depending on participant reference and broader context.

- Support of administrative staff to follow-up with health professionals about clients being tracked. A memorandum of understanding with partner services to reimburse services for administrative staff time.

- A key contact person at each service is important to liaise with health professionals in the communication of the methods and stages of data collection. 
For the depression case tracking, completing the questionnaires through meeting face-to-face with health professionals was effective in yielding rich qualitative reflections on how the sessions went, what went well, what could have been done differently. This section was also useful in highlighting barriers such as clients' complex adverse social determinants that they felt were beyond their control and health system barriers to comprehensive PHC provision, such as chronic conditions being prioritised over mental health, and pressure to limit the number of sessions they provided to clients. Tomison and Goddard $^{9}$ also found that interviews yielded richer quality data than paper-based questionnaires. Following up with health professionals to complete questionnaires was a time-consuming task. Tomison and Goddard ${ }^{9}$ used the strategy of regularly visiting staff to keep them motivated, which served as a reminder to complete questionnaires; however, in our study resources did not allow this.

Supportive administrative staff were critical to the success of tracking clients with diabetes at services A and $\mathrm{C}$, where case tracking was most successful. The project had a memorandum of understanding with the partner services that included arrangements to reimburse services 0.1 FTE of administrative staff time a year for participating in the research, and this proved crucial to gaining this administrative support at the sites. Successful case tracking also relied on having a dedicated key contact person at the services, such as a diabetes nurse educator or a social worker. It was also important that we were able to be flexible with health professionals' workloads. For example, the addition of 10 new clients per month to the list of case-tracked clients with diabetes was paused at one site for a period of 4 months as workloads became too high, and was then resumed again when workloads reduced.

Being flexible with this pilot method was a key component to its success as it was able to be adapted across the different sites which varied greatly in size and composition, a feature of the nature of Australian PHC. This was evident at Congress where the method was negotiated and varied to the other services. The benefits of using electronic case notes were that the notes obtained from Communicare were quite detailed, and there were no concerns of completeness or health professional's workload. However, case notes did not include qualitative reflective data gathered at the other services.

\section{Challenges in using the case-tracking method}

The research occurred at a time of considerable restructure and reorientation of South Australian PHC, ${ }^{24}$ affecting four of our five case study services (Congress being based in the Northern Territory). Such restructuring is not uncommon in health services, but provides a threat to research in health services when service continuity is low, what is being studied is in flux and health professional turnover is high. Engaging health professionals in this research was at times difficult. Barriers included competing demands on their time, low morale, high levels of stress and turnover, with a number that worked part time or were on very short-term contracts (eg, 3 months). Health professionals were less motivated to be involved in this research and some, particularly parttime staff, declined to participate in the study.

There were specific challenges in using this pilot casetracking method for clients with depression. Staff were reluctant to invite clients into the interview component of the study during initial appointments as clients were considered too vulnerable and often very distressed. At some services, the period of care offered to clients was quite short and delaying the invitation to participate sometimes meant it was too late; clients had often finished counselling or did not return to the service. At some services, particularly A and C, there were very few mental health workers employed, partly due to the reorientation of services towards physical chronic conditions which was part of the restructuring of services, and this reduced the ability to capture the work of a multidisciplinary team.

There were some limitations in this pilot application. Client journeys were restricted to individual PHC services as it was beyond the scope of this study to track clients across services. This is a reflection of the complex nature of health service delivery structures that constitute the Australian health system with a fragmented mix of public and private funds shared between the states, federal and local governments with poor centralisation records between state and federal governments. The research was envisioned as an action research project, but reorganisation at most sites meant it was difficult to provide any key research findings to the health services. Our case-tracking sampling was largely able to avoid selection biases, with all depression clients included, and techniques such as a random sample of 10 new clients per month. This was not possible for the client interviews, and selection biases may have been introduced by staff making judgements about which clients to ask to participate. Also, while health professionals did refer to client case notes to complete the case-tracking questionnaires, they also relied on memory so there may have been some underreporting of information such as referrals.

\section{CONCLUSION}

Despite some difficulties, the pilot case-tracking methods and client interviews were useful in generating individual depression and diabetes client journeys. It provided important information about the range of comprehensive PHC actions services undertook to respond to these conditions, and on client experiences using comprehensive PHC services through the care trajectory. The client journeys were successful in capturing important aspects unique to comprehensive PHC, such as addressing the social determinants of health through client advocacy. This is important as details about the ways health services respond to the challenges of clients' social determinants of health are rarely reported in the literature, and the need for innovative ways of capturing advocacy, 
cultural sensitivity and actions likely to promote equity has been noted by Levesque et al. ${ }^{30}$ These pilot casetracking methods proved feasible and can be applied by any health service of variable size wanting to examine the comprehensiveness of models of care, collaboration and communication among health professionals, referrals to other services and possible gaps in care. In particular, this method is useful in highlighting the extent to which services are responding to clients' needs through strategies such as advocacy and action on social determinants of health, to inform service planning and practice, with the potential to improve health system integration. Future research could apply the method to other chronic conditions to examine client pathways and highlight gaps in service delivery and coordination with other services.

Acknowledgements The authors appreciate the involvement of staff and clients at the five PHC services for participating in this study. We would also like to acknowledge Pei-Hua Tsai for her valuable contributions to the creation of the client journey diagrams, and Bronwyn Veale for her advice on the client healthcare logs.

Contributors EB carried out the depression component of the study which includes the data collection, generation of client journeys, and developed the framework for analysing the client journeys and conducted the analysis of the depression client journeys. TF carried out the diabetes component of the study including the data collection, led the generation of client journeys and their analysis. EB wrote the drafts and final version of the manuscript. TF wrote the diabetes case-tracking method and made significant contributions to all versions including the final version of this manuscript. FB, AL and SJ contributed to study design, data collection and data analysis, and made significant contributions to the manuscript. All authors read and approved the final manuscript.

Funding This work was supported by a National Health and Medical Research Council grant number 535041

Disclaimer The client names referred to in this article are ficticious to protect the identity of participants.

Competing interests None declared.

Patient consent for publication Not required.

Ethics approval Ethics approval was received from the Southern Adelaide Clinical Human Research Ethics Committee (499.11), Aboriginal Health Research Ethics Committee (04-12-429) and SA Health Human Research Ethics Committee (486/11/2014). Both staff and clients signed consent forms to participate in this research.

Provenance and peer review Not commissioned; externally peer reviewed.

Data sharing statement The datasets generated and/or analysed during this study are not publicly available due to anonymity and privacy concerns.

Open access This is an open access article distributed in accordance with the Creative Commons Attribution Non Commercial (CC BY-NC 4.0) license, which permits others to distribute, remix, adapt, build upon this work non-commercially, and license their derivative works on different terms, provided the original work is properly cited, appropriate credit is given, any changes made indicated, and the use is non-commercial. See: http://creativecommons.org/licenses/by-nc/4.0/.

\section{REFERENCES}

1. Kuo S, Huang KE, Davis SA, et al. The rosacea patient journey: a novel approach to conceptualizing patient experiences. Cutis 2015;95:37-43.

2. Leeder S. An ideal patient journey in a reformed health service, in Australian Healthcare Reform Alliance Conference. Sydney: NSW, 2007.

3. Doherty D, Benbow SM, Craig J, et al. Patients' and carers' journeys through older people's mental health services: Powerful tools for learning. Dementia 2009;8:501-13.

4. Lapsley P, Groves T. The patient's journey: travelling through life with a chronic illness. BMJ 2004;329:582-3.
5. Campbell S, Watson B, Gibson A, et al. Comprehensive service and practice development: city hospitals Sunderland's experience of patient journeys. Practice Development in Health Care 2004;3:15-26.

6. Grant P, Chika-Ezerioha I. Evaluating diabetes integrated care pathways. Practical Diabetes 2014;31:319-22.

7. Hall J, Callaghan P. Focus group study of service user and carer experience of an Integrated Care Pathway. Int J Care Pathw 2011;15:44-8.

8. Lloyd C, King R, Bassett $\mathrm{H}$, et al. Patient, Client or Consumer? A Survey of Preferred Terms. Australasian Psychiatry 2001;9:321-4.

9. Tomison A, Goddard CR. Blending qualitative and quantitative approaches: case tracking studies in child protection systems.. in Issues of rigour in qualitative research 1999.

10. Goddard CR. A child sexual abuse police tracking project: A hospitalbased study for the Law Reform Commission of Victoria, in Law Reform Commission of Victoria, Sexual offences against children: Research reports. Melbourne: Victorian Government Printers, 1988:61-185

11. Goddard CR, Hiller PC. Tracking physical and sexual abuse cases from a hospital setting into Victoria's criminal justice and child protection systems - A report for the Victorian Law Foundation Nols 1-3). Melbourne: Departments of Social Work \& Anthropology \& Sociology, Monash University, 1992.

12. Goddard CR. A provisional analysis of decision-making by statutory child protection workers in a rural context. Melbourne: Child Abuse and Family Violence Research Unit, 1996.

13. Hiller M, Goddard CR, Diemer KM. 98 cases of child abuse presenting at a major Melbourne hospital: Socio-demographic factors and institutional reactions (Vols. 1-2). Melbourne: Departments of Anthropology \& Sociology, and Social Work, Monash University, 1991.

14. Trebble T, et al. Process mapping the patient journey through health vare: an introduction. British Medical Journal 2010;341:394-7.

15. Jackson K, Oelke ND, Besner J, et al. Patient journey: implications for improving and integrating care for older adults with chronic obstructive pulmonary disease. Can J Aging 2012;31:223-33.

16. Piacentini J, Rotheram-Borus MJ, Gillis JR, et al. Demographic predictors of treatment attendance among adolescent suicide attempters. J Consult Clin Psychol 1995;63:469-73.

17. Oliver S, Bosworth A, Airoldi M, et al. Exploring the healthcare journey of patients with rheumatoid arthritis: a mapping project implications for practice. Musculoskeletal Care 2008;6:247-66.

18. Richards DA, Bower P, Pagel C, et al. Delivering stepped care: an analysis of implementation in routine practice. Implement Sci 2012;7:3.

19. World Health Organization,. Declaration of Alma-Ata, International Conference on Primary Health Care, USSR, 6-12. Alma Ata: World Health Organization, 1978.

20. Baum F. The New Public Health. 5th ed. Melbourne: Oxford University Press, 2016.

21. Gallant MP. The influence of social support on chronic illness selfmanagement: a review and directions for research. Health Educ Behav 2003;30:170-95.

22. Freeman T, Baum F, Lawless A, et al. Revisiting the ability of Australian primary healthcare services to respond to health inequity. Aust J Prim Health 2016;22:332-338.

23. Freeman T, Baum FE, Jolley GM, et al. Service providers' views of community participation at six Australian primary healthcare services: scope for empowerment and challenges to implementation. Int $J$ Health Plann Manage 2016;31:E1-E21.

24. Jolley G, Freeman T, Baum F, et al. Health policy in South Australia 2003-10: primary health care workforce perceptions of the impact of policy change on health promotion. Health Promot J Austr 2014;25:116-24.

25. Veale B, ed. Continuity of care and general practice utilisation in Australia. Australia: Australian National University, 1996.

26. Lawless A, Freeman T, Bentley M, et al. Developing a good practice model to evaluate the effectiveness of comprehensive primary health care in local communities. BMC Fam Pract 2014;15:99.

27. Miles MB, Huberman AM, Saldana J. Qualitative data analysis: a methods sourcebook. . A Methods Sourcebook: Qualitative Data Analysis, 2014:86. 275-322.

28. Ritchie J, Spencer L, Bryman A, et al. In: Bryman A, Burgess RG, eds. Qualitative data analysis for applied policy research, in Analyzing qualitative data. London: Routledge, 1994.

29. Guba E, Lincoln Y. Fourth generation evaluation: Sage, 1989.

30. Lévesque JF, Haggerty J, Beninguissé G, et al. Mapping the coverage of attributes in validated instruments that evaluate primary healthcare from the patient perspective. BMC Fam Pract 2012;13:1. 